\title{
The effect of the rand exchange rate on the JSE Top-40 stocks - An analysis for the practitioner
}

\author{
G.D.I Barr*, B.S. Kantor and C.G. Holdsworth \\ Respectively, Department of Statistical Sciences and Economics, \\ Department of Economics and Chief Strategist, Investec Securities and Research, \\ Department of Statistical Sciences, University of Cape Town \\ Private Bag, Rondebosch 7701, Republic of South Africa \\ gdi@iafrica.com
}

Received October 2006

\begin{abstract}
This paper investigates the relationship between the returns of the ALSI Top 40 companies and changes in the RandDollar exchange rate. Each of the Top 40 companies was grouped, a priori, according to their global positioning vis-à-vis income and costs into four main categories; namely, Rand-hedge, Rand-leverage, Rand-play and Mixed. The expected reaction of each of the shares within these categories to movements in the exchange rate was in almost all cases confirmed by GARCH adjusted regression analysis over two separate periods, February 1999 to January 2002 and February 2002 to August 2005. Ranked t-statistics were then used to gauge the consistency of the risk-adjusted magnitude of share price changes with respect to changes in the exchange rate. This ranking allows investors to construct customised portfolios according to their expectation of future exchange rate movements and to more fully understand the exchange rate risk that their current portfolio may have.
\end{abstract}

*To whom all correspondence should be addressed.

\section{Introduction}

The period between 2000 and 2004 has been one of extreme movements in the nominal and real value of the Rand and, as a result, the effect of the Rand exchange rate on individual stocks and the market at large has received increasing attention. In fact, most financial commentary sees the behaviour of the Rand as the key economic variable in any assessment of the future behaviour of the market and its component stocks. In addition, particularly since the recent three year period of exchange rate strength, financial commentary has been pointing to the JSE as a means through which individuals can protect the foreign currency value of their Rand denominated wealth.

Less structured commentary has been devoted to how a portfolio could be constructed to give the particular type of exchange rate protection that investors may desire. Unit Trusts have been set up which are intended to give protection against Rand weakness (generally with portfolios of resource stocks) or that are able to take advantage of Rand strength (generally banks and retailers). However, there is less definitive work on the relative merits of the top JSE stocks in terms of their Rand sensitivity and their past performance with respect to Rand movements.

In this paper we take a Top40 selection of stocks and consider in detail, using an appropriate statistical model, the relative Rand sensitivity of stocks. This analysis allows an investor to pick particular stocks with particular Rand sensitivity characteristics as well as particular market risk. These Rand (and market) betas would then allow that investor to more finely select a portfolio with risk-return characteristics that were fully consistent with the individual's future view on the Rand.

\section{Overview of the paper}

This paper draws on a previous paper (Barr \& Kantor, 2005) which gives a comprehensive treatment of the theoretical economic model underlying this analysis. In contrast, this paper has an empirical focus and concentrates primarily on establishing, for the practitioner, the exchange-ratesensitivity ranking of the JSE Top40 stocks. We begin by explaining how most JSE stocks can be broken down into four different categories according to the nature of their core underlying business, these being Rand-leverage, Randhedge and Rand-play stocks (a rigorous treatment of this issue is given in an Appendix). Although the majority of stocks fall quite clearly into one of these categories, a number of diversified industrial stocks, holding companies and companies whose business is primarily but not exclusively based overseas are not so easily categorised. Taking the consistent Top40 members over the last four years we form prior positions on the nature of their share price sensitivity to the exchange rate based on these categorisations. We then describe the various models that were considered in an attempt to most appropriately measure the exchange rate sensitivity of share prices. The empirical results are then presented, which give, for the most successful model considered, the sensitivity to exchange rate movements and market wide movements. These results are then considered for their robustness over different periods and, in particular, the consistency of their (reliability) rankings is shown graphically. 


\section{The effect of the rand on different stocks}

Mining and Resources companies, which account for close to $50 \%$ of the JSE's market value, respond very differently to Rand weakness or strength. They tend to lose Rand value when the Rand appreciates and gain Rand and US\$ value when the Rand depreciates. This is because they earn almost all their revenue from the minerals and metals they produce that are priced in US\$ from mostly offshore customers and their costs are predominantly in Rand.

But these Rand effects on operating margins are matters of degree. Many of the (mostly) Rand-play companies have divisions, and sometimes also foreign currency debt, to further complicate their reactions to the Rand and its accounting treatment. Furthermore, the domestic market can also be very important for some JSE-listed Resources companies, as it is for Sasol (SOL) and Mittal-Steel (MLA). These companies, given the lack of domestic competition, are able to charge their customers in South Africa worldmarket, US\$-related import parity prices. They charge lower, export parity prices in export markets. Thus the more production they can allocate to the South African market the more profitable they will be for any given level of the Rand. These companies therefore also depend on the strength of the SA economy and world economies, as well as on the foreign exchange value of the Rand itself for their bottom lines.

The revenues of Resources companies, and especially Mining companies serving foreign markets, are generated in US\$ while a large component of their costs constitute labour costs and are denominated in Rand. Hence if the Rand depreciates, their labour costs (in \$) fall and for any given level of commodity prices, their margins improve. Similarly, as has happened recently, if the Rand appreciates their labour costs rise and their margins deteriorate. In normal times on the currency markets, unlike the events between 2000-2003, when the Rand collapsed and then fully recovered its losses, the Rand can be expected to move in line with commodity prices which moderates the impact of the US\$ commodity price cycle on SA Resources companies. However, the favourable impact of higher commodity prices would not be expected to be vitiated by the resulting Rand strength (and vice versa). In fact, Khoo (1994:349, 356), in a study examining the foreign exchange exposure of mining companies in Australia, suggested that the effect of foreign exchange fluctuations could be dampened or even reversed - either incidentally by a company's business practice, such as exporting goods and importing equipment or deliberately by holding currency positions. These and other equivalent activities may change the company's exchange-rate exposure and need to be examined before classifying the company.

\section{Literature review}

The actual measurement of the impact of the Rand on JSE stocks has not been considered in the literature. There is a relatively small body of literature examining the exchange rate exposure of shares and most of it is focused on the Australian case.
Adler and Dumas (1984) produced a definition for exchange rate exposure in the case of Australian shares and mentioned that even domestic firms with no dealings in foreign exchange can be exposed to an exchange rate through the exposures of their clients. They proposed that the best manner of measuring this exposure is through a regression coefficient of the share price on a specific set of exchange rates. In the US case, Jorion (1990) showed that differences in exposure to the exchange rate occurred between U.S. multinationals, and that this was related to the level of foreign sales - these conclusions were supported by work done by Choi and Prasad (1995). Jorion (1991) added a market term to the regression and orthogonalised the exchange rate to avoid multicollinearity. He found that exchange rate risk was diversifiable.

The difference in reaction between Resources and Industrials to exchange rate fluctuations was considered in the Australian case by Loudon (1993), who found there to be a significant difference in their behaviour over the period 1984-1989. The paper came to the predictable conclusion that listed Australian resource companies benefited from an exchange rate depreciation, while industrials benefited from an appreciation. Bodnar and Gentry (1993) considered the markets in Japan, Canada and the USA and went on to classify industries' exchange rate exposure according to their mode of operation, e.g. exporter, importer, foreign investor. Khoo (1994), in a study examining the foreign exchange exposure of mining companies in Australia from January 1980 to March 1987, found that, in general, share returns were not sensitive to exchange rates. Di Orio and Faff (2001) looked at the stability of exchange rate exposure in the Australian market and found there to be evidence of exposure changing over time periods. They suggested that this could be the reason for previous studies finding relatively weak exposure, as long time periods could have averaged out the exposure. Benson and Faff (2003), in a study on Australian international equity trusts, also found there to be instability in exchange rate exposure. Dominguez and Tesar (2001) showed that for Chile, France, Germany, Italy, Japan, Netherlands, Thailand and the UK the use of a trade weighted exchange rate will result in lowered estimates of exposure as it contains currencies to which individual companies may not be exposed.

\section{The South African case}

In the local financial community, the term Rand-hedge is commonly applied to all those companies that benefit in Rand value terms from Rand weakness. However, because at any stage of the commodity cycle the margins of resource companies expand and contract with the Rand and the effect is both on revenue and cost, we are inclined to refer to such companies as Rand-leveraged rather than Rand-hedged.

We prefer to apply the term Rand-hedge to companies listed on the JSE that have largely or only hard currency revenues and hard currency costs. This makes their economic performance, whether measured in Rand or US\$ or any other currency, largely independent of the South African economy. The best examples of such companies are luxury goods and tobacco company Richemont (RCH) and Liberty International (LBT), a London-based property developer. 
The US\$ earnings of RCH or LBT have almost nothing to do with the value of the Rand. Thus it may be thought that their US\$ values would simply be translated into Rand values at prevailing exchange rates - going up and down proportionately with the Rand, thus making them pure Rand-hedges. However, it should be recognised that for companies with a large constituency of South African shareholders, less or more anxiety about the Rand will be an additional influence on their Rand and US\$ values.

JSE-listed companies' offshore investment activities have produced a further type of listed company that may be described as Rand neutral, i.e. one that maintains stable Rand values in the face of changes in the exchange rate. They are able to do this because they have a roughly equal mix of earnings from South African and offshore assets. Remgro (REM), with half its balance sheet consisting of SA Banks and half of international tobacco, is one such important company. Investec (INL and INP) and Old Mutual (OML) with very important operating subsidiaries offshore may now also be classified as Rand neutral. What they gain (lose) in Rand revenues from a weaker (stronger) Rand offshore, they lose (gain) in Rand from their onshore operations. Their Rand values now appear to be largely unaffected by changes in the value of the Rand. Barloworld is a diversified industrial company that has both Rand-hedge and Rand-play characteristics. Imperial, another diversified industrial, differs from Barloworld in the allocation of its capital and is regarded here as a Rand-play. SAB-Miller (SAB) has in recent years become an international brewer with a large proportion of its assets offshore. We therefore classify $\mathrm{SAB}$ as an additional Mixed company as a very significant proportion of its earnings is still generated in South Africa. This still makes SAB partially dependent on SA demand for its products and therefore on the SA economy. A strong SA economy and a strong Rand and what it means for beverage sales is naturally good for SAB, but not as good for its shareholders had it remained a South African brewery. Such considerations apply also to paper manufacturer Sappi (SAP) and a number of the subsidiaries of Anglo American for whom the South African market is important.

\section{The sample of shares considered}

The constituents of the JSE Top40 are not fixed, since the Top40 index comprises the Top 40 shares by market capitalisation and therefore membership of the Top40 group of shares is linked to price. We consider those members of the JSE Top40 who have remained consistently in the Top40 grouping over the past four years and categorise them according to an a priori classification on their response to changes in the Rand exchange rate.

Table 1 below lists the shares included in the analysis, their weight in the Top40 and their expected categorisation with respect to the currency as Rand-play, Rand-hedge, Randleverage or mixed (that is, no fixed prior position).

\section{Empirical analysis}

In this section we consider the empirical determination of the sensitivity of the share price movements to movements in the Rand exchange rate. The computation of the sensitivity of stocks to market-wide movement (the socalled 'financial beta') has been an issue of empirical calculation that has received considerable attention in the financial literature at large and in local financial research; see, for example Barr and Bradfield (1989) and Bowie and Bradfield (1993). There has, however, been little academic attention given to the specific sensitivity of stocks to the Rand exchange rate.

The statistical models used were of the general form, with all data in monthly form

$\%$ Top $0_{\text {it }}=\alpha+\beta_{1} \%$ RExch $_{\mathrm{t}}+\beta_{2} \%$ Market $_{1 \mathrm{t}}+\beta_{3} \%$ Market $_{2 \mathrm{t}}+\mathrm{e}_{\mathrm{it}}$

where:

$\% \mathrm{Top} 40_{\text {it }}$ is the continuously compounded percentage change of the $i$-th component of the Top40;

$\% \mathrm{RExch}_{\mathrm{t}}$ is the continuously compounded percentage change of the Rand exchange rate;

$\%$ Market $_{\text {it }}, \mathrm{i}=1,2$ is the continuously compounded percentage change of (up to) two market wide indices.

$\mathrm{e}_{\mathrm{it}}$ is usually assumed to have zero expectation, constant variance $\left(\sigma^{2}\right)$ and $\mathrm{E}\left(\mathrm{e}_{\mathrm{it}}, \mathrm{e}_{\mathrm{it}-\mathrm{k}}\right)=0, \forall k=1,2, \ldots ; \forall i$.

In the first instance, ordinary least squares regression was used to estimate the relationship between log-returns of stocks and a set of independent variables which always included the exchange rate and in addition included market variables to capture market wide effects. The estimated beta coefficients represent elasticities as all the variables are in continuously compounded percentage and hence represent the (estimated) percentage movement in the share price stemming from a $1 \%$ move in the independent variable. The associated t-value effectively adjusts the beta for reliability (estimation uncertainty) and gives an indication of the confidence with which one can rate the beta as positive or negative. The ranking of the exchange rate t-statistics then gives a direct statistical indication of the relative statistical robustness of share price movement with respect to the exchange rate. The use of ranking is an attempt to move away from the often discredited approach of simply looking at statistical significance; see, for example, Ziliak and McCloskey (2004). By ranking t-statistics of exchange rate effects, we are making no definitive statement about whether the exchange rate effects for each share are individually significant at some level. In the spirit of Ziliak and McCloskey, we are simply considering the relative magnitudes of the statistics themselves. This ranking of tstatistics could then be used by investors as a guide to the empirical hierarchy of exchange rate effects amongst the JSE Top Forty stocks. This, in turn, could be used as a guideline by investors as to the shares which would, for example, give the most protection from rand weakness. 
Table 1: Sample of shares considered

\begin{tabular}{|c|c|c|c|c|c|}
\hline Ticker & Name & Sector & Prior Expectation & $\begin{array}{l}\text { \%Top40 by } \\
\text { Mkt Cap } \\
\text { (approx) }\end{array}$ & $\begin{array}{c}\text { Mkt. Cap. } \\
\text { Rank }\end{array}$ \\
\hline ASA & ABSA Bank & Banks & Rand-play & 2,78 & 13 \\
\hline FSR & First Rand & Banks & Rand-play & 4,35 & 7 \\
\hline IPL & Imperial Holdings Ltd & Diversified Industrials & Rand-play & 1,29 & 26 \\
\hline LGL & Liberty Group Ltd & Life Assurance & Rand-play & 1,04 & 28 \\
\hline MTN & MTN Group Ltd & Wireless Telecom Servicies & Rand-play & 3,50 & 9 \\
\hline NED & Nedcor Ltd & Banks & Rand-play & 1,68 & 19 \\
\hline NPK & Nampak & Business Support Services & Rand-play & 0,64 & 34 \\
\hline NPN & Naspers Limited & Cable \& Satellite & Rand-play & 1,15 & 27 \\
\hline NTC & Network Healthcare Services & Hospital Management & Rand-play & 0,62 & 35 \\
\hline PIK & Pick n Pay & Food \& Drug retailers & Rand-play & 0,74 & 32 \\
\hline RMH & RMB Holdings & Banks & Rand-play & 1,48 & 21 \\
\hline SBK & Standard Bank Group & Banks & Rand-play & 4,79 & 6 \\
\hline SLM & Sanlam Limited & Life Assurance & Rand-play & 1,94 & 18 \\
\hline TBS & Tiger Brands Limited & Food Processors & Rand-play & 0,95 & 29 \\
\hline TKG & Telkom SA Limited & Fixed Line Telecom Services & Rand-play & 3,03 & 12 \\
\hline VNF & Venfin Limited & Investment Companies & Rand-play & 0,65 & 33 \\
\hline WHL & Woolworths Holdings Ltd & Retailers - Multi Department & Rand-play & 0,60 & 36 \\
\hline BAW & Barloworld Ltd & Diversified Industrials & Mixed & 1,29 & 25 \\
\hline BVT & The Bidvest group & Business Support Services & Mixed & 1,48 & 22 \\
\hline INL & Investec Limited & Investment Banks & Mixed & 0,41 & 37 \\
\hline OML & Old Mutual Plc & Life Assurance & Mixed & 3,27 & 10 \\
\hline REM & Remgro Limited & Investment Companies & Mixed & 2,72 & 14 \\
\hline SAB & SAB Miller Plc & Beverages - Brewers & Mixed & 5,83 & 4 \\
\hline SHF & Steinhoff International Holdings & Furnishings \& Floor Coverings & Mixed & 0,80 & 31 \\
\hline LBT & Liberty International Plc & Real Estate Holdings \& Development & (pure) Rand-hedge & 2,02 & 17 \\
\hline $\mathrm{RCH}$ & Richemont Securities Ag & Household Appliances \& Housewares & (pure) Rand-hedge & 5,88 & 3 \\
\hline AGL & Anglo American Plc & Metals \& Minerals & Rand-leverage & 12,96 & 1 \\
\hline AMS & Anglo American Platinum Corp & Platinum & Rand-leverage & 3,26 & 11 \\
\hline ANG & Anglo Gold Limited & Gold Mining & Rand-leverage & 3,86 & 8 \\
\hline BIL & BHP Billiton Plc & Metals \& Minerals & Rand-leverage & 9,94 & 2 \\
\hline GFI & Gold Fields Limited & Gold Mining & Rand-leverage & 2,49 & 15 \\
\hline HAR & Harmony Gold Minimg Ltd & Gold Mining & Rand-leverage & 1,44 & 23 \\
\hline IMP & Impala Platinum Holdingss Ltd & Platinum & Rand-leverage & 2,11 & 16 \\
\hline MLA & Mittal SA & Steel & Rand-leverage & 1,59 & 20 \\
\hline KMB & Kumba Resources Ltd & Metals \& Minerals & Rand-leverage & 0,83 & 30 \\
\hline SAP & Sappi Limited & Paper & Rand-leverage & 1,33 & 24 \\
\hline SOL & Sasol Ltd & Oil - Integrated & Rand-leverage & 5,25 & 5 \\
\hline
\end{tabular}




\section{Choice of independent variables}

Two candidates for \%RExch were considered, the first being the nominal effective Rand exchange rate, which is a trade weighted nominal exchange rate and generally regarded as appropriate when dealing with the economywide impact of exchange rate effects. The second is the familiar $\mathrm{R} / \$$ exchange rate which was seen as appropriate in this context because so many commodity prices are denominated in US dollars. However, for both periods the correlation between the two exchange rate series was over 0.98 . The two derived beta estimates did not differ widely but the $\mathrm{R} / \mathrm{S}$ exchange rate tended to give better overall fits and significance and was therefore used in the analysis. This is consistent with Dominguez and Tesar (2001) who showed that for Chile, France, Germany, Italy, Japan, Netherlands, Thailand and the UK the use of a trade weighted exchange rate will result in lowered estimates of exposure as it contains currencies to which individual companies may not be exposed.

Two model configurations were used for the market-wide effects. Firstly a straightforward JSE Overall index to capture market-wide movements on the JSE. Secondly a model which included two market-wide effects, the MSCI to capture world effects (in US\$) and a secondary EmergingMarket-Index (EMI) denominated in US\$ to capture effects pertinent to an emerging market. In the second case, the world effect (MSCI) was removed from the EMI by first regressing (all variables in Log return form) the EMI on the MSCI and working with the residuals.

However, the configuration with one independent variable (JSE Overall Index) consistently gave a better explanation $\left(\mathrm{R}^{2}\right)$ than the configuration with the MSCI and EMI indices as independent variables. In addition, using the $\mathrm{R} / \mathrm{S}$ exchange rate as the exchange rate variable also consistently gave better results to those using the effective (tradeweighted) exchange rate. The only results reported here are those with the $\mathrm{R} / \$$ exchange rate and the JSE Overall index as independent variables.

As discussed above, the movement of the JSE as a whole is inextricably linked to the movement of the Rand exchange rate. Thus, having both the overall market and the dollar Rand exchange rate as explanatory variables may be expected, at least in part, to give rise to a problem of multicollinearity between these two explanatory variables. Although not a strict statistical assumption for Ordinary Least Squares regression (OLS), multicollinearity, especially when severe, will lead to instability (and high associated variances) in the estimates of the coefficients as the OLS procedure has difficulty in distinguishing the variables (see, for example, Johnson, Johnson \& Buse, 1987).

In order to assess the severity of any multicollinearity, the correlation between the continuously compounded percentage change of the Rand Dollar exchange rate and the top40 was estimated over both periods. Values for the first and second period of $-0,082$ and 0,354 respectively were obtained, which were tested for significance using the Fisher-z transformation. The resulting $\mathrm{z}$ values showed there to be insignificant correlation in the first period ( $p$ value of 0.638 ) but significant correlation in the second period ( $p$ value of 0.020). Even though the correlation values were relatively small, the significant value in the second period implied that removing multicollinearity should be considered.

An often used technique to circumvent any possible consequences of multicollinearity is to orthogonalise the two independent variables (see, for example, Benson and Faff (2003:101), Youguo and Mbodja (1996), Choi and Prasad (1995:78) and Jorion (1991:366), who orthogonalised the exchange rate term variable with respect to the overall market). Both forms of possible orthogonalisation were considered here; that is, the removal of the market effect from the exchange rate and the removal of the exchange rate from the market. The results from the original, unorthogonalised model and the two different orthogonalised models were then compared for each stock. The differences for the coefficients and t statistics of the log differences of the top40 and $\mathrm{R} / \mathrm{S}$ exchange rate were, however, found to be small. Given this and the fact that the true generating process is unknown, and since the process of orthogonalising the variables may bias the estimates (see, for example, Giliberto (1985)), only the results of the unorthogonalised model are reported here.

It has also been recognised in the literature (Mandelbrot (1963), Fama (1965)), that financial markets are frequently characterised by volatility clustering as information with uncertain implications permeates into markets and that explicitly modelling this effect as a generalized autoregressive conditional heteroscedasticity model (GARCH model) is appropriate. For example, Bollerslev, Chou and Kroner (1992) have shown how ARCH/GARCH ${ }^{1}$ models may be applied to modelling volatility and Brooks, Davidson and Faff (1997) have applied ARCH/GARCH models for modelling volatility in the JSE specifically. Di Iorio and Faff (2001) fitted a GARCH $(1,1)$ term to model volatility clustering in the residuals of shares in Australia after fitting a term for the market, an exchange rate term and a lagged exchange rate term and found it to be significant in all cases. Even though volatility persistence tends to be more apparent in high frequency (such as daily) data than in the monthly data used here, it was considered appropriate here to adjust the error term using a $\operatorname{GARCH}(1,1)$ term. The model used is of the form:

$\sigma_{\mathrm{it}}^{2}=\omega_{\mathrm{i} 0}+\omega_{\mathrm{i} 1} \varepsilon_{\mathrm{i}, \mathrm{t}-1}^{2}+\omega_{\mathrm{i} 2} \sigma_{\mathrm{i}, \mathrm{t}-1}^{2}$,

where:

$\sigma_{\mathrm{it}}^{2}$ - variance of the residual for share $i$ at time $t$,

$\varepsilon_{\mathrm{it}}$ - is assumed to have zero expectation, be homoscedastic and independent over time.

\footnotetext{
${ }^{1}$ The original ARCH model was introduced by Engle (1982); and the Generalized ARCH or GARCH model was introduced by Bollerslev (1986).
} 


\section{The empirical results}

The betas are calculated for this model (with the GARCH(1,1) error term adjustment) over two distinct periods to compare the consistency and robustness of the results. As the severe volatility of markets in the latter half of 1998 following the emerging market crisis made estimating any betas unreliable, it was decided to focus on the period subsequent to this period. Hence two sets of betas are presented - for the periods February 1999 to January 2002 and for the period February 2002 to August 2005. These are listed below in Table 2 in the same order as the $a$ priori categorisation table (Table 1) presented earlier. The larger the estimated exchange rate beta, the greater the degree of responsiveness of the share price returns to changes in the value of the Rand (in the same direction if the beta is positive, and in the opposite direction if beta is negative). However, because it is important to adjust for estimation uncertainty, we suggest that a more relevant variable in assessing exchange rate sensitivity is the associated t-statistic. In this way, measuring the t-statistic parallels the use of the Sharpe ratio (reward to variability ratio) for assessing portfolio performance (see Sharpe (1994)) and gives the number of standard deviations by which the estimated coefficient differs from zero. The table also includes the $\mathrm{R}^{2}$ statistic as a measure of overall model fit. Note that in this context, an $\mathrm{R}^{2}$ value that is in excess of 0.35 would be considered good. Inherent share price volatility for actively traded stocks implies that a considerable percentage of movement is very difficult to explain statistically. Hence, it is seen from Table 2 that for the shares considered, the model fits can be regarded in most cases to range from good to very good.

Encouragingly, particularly in the recent period, there is close congruence between the a priori expected sign of the exchange rate effect and the sign of the estimated exchange rate effect. The only exceptions are VNF in the first period, NTC, ANG and MLA. These values are not large in their sign and could be evidence of hedging or other confounding factors such as MLA charging import parity prices - thus if the Rand weakens steel becomes more expensive for the South African market and demand may decrease. There may well be other effects, but as long as they are consistent, it becomes irrelevant and their exposure and ranking will remain consistent. Again, we emphasise that that this treatment of considering the ranked t-statistics is in the spirit of the recent work by Ziliak and McCloskey (2004); that is we de-emphasise the statistical significance or otherwise of the coefficients and focus upon the ranking, and consistency of the rankings of the actual t-statistics.
The three Figures below (Fig. 1, Fig. 2 and Fig. 3), comprise for each of the three a priori classification categories, namely Rand-plays, Mixed and Rand-leverage \& Randhedge, the plot of the empirical exchange rate t-statistics over the two periods considered. As has been explained above, since it is the actual ranking of the exchange rate effect which is of primary importance, t-statistics are deemed to be more useful in this context than simply looking at straightforward coefficient estimates, as tstatistics adjust for the reliability of the coefficient estimates (see, for example, Green (1987)). The Figures thus give one an idea of the consistency of the empirical ranking of the Rand-exchange rate sensitivity adjusted for uncertainty amongst the shares considered over the two different periods. Considering these three Figures we may note the following:

\section{Rand-plays}

All shares in the recent period, with the exception of NTC, have a negative exchange rate beta as expected. In terms of t-stats it is seen from the Figure that the banks represent particularly reliable Rand-play shares followed by the retailers. Note that the ranking, particularly in terms of the Bank and Retail grouping remains consistent across the two periods. Telkom, a share that is sensitive to the dollar cost of telecommunications equipment, has recently entered the market as a key Rand-play, similar to MTN.

\section{Mixed}

According to our classification, it may be seen that these companies, as expected, have a degree of individualism in respect of the Rand exchange rate sensitivity and that the ranking is not particularly consistent across time. Most are effective Rand-plays, the notable exception being Steinhoff, a large vertically-integrated furniture manufacturer with plants in South Africa and elsewhere and with a large proportion of its sales made outside South Africa. The industrial conglomerates Barloworld, Imperial and Bidvest all behave as effective Rand-plays even though a fair proportion of their business benefits from Rand weakness. South African Breweries comes through as a weak Randplay reflecting the fact that they still manage a significant proportion of SA-domiciled assets and earn a disproportionate share of their profits from local operations. Remgro is fairly Rand neutral, comprising as it does a mix of a large (close to 50\%) holding in BAT (British American Tobacco) as well as significant holdings in First Rand and ABSA. 
Table 2: Empirical estimates of rand sensitivity using a GARCH(1,1) adjustment

\begin{tabular}{|c|c|c|c|c|c|c|c|c|c|c|}
\hline \multicolumn{11}{|c|}{ Empirical estimates of rand sensitivity } \\
\hline & \multicolumn{5}{|c|}{ Feb 1999 - Jan 2002} & \multicolumn{5}{|c|}{ Feb 2002 - Aug 2005} \\
\hline & R/\$ Beta & t-stat & Top40 Beta & t-stat & $\mathbf{R}^{2}$ & R/\$ Beta & t-stat & Top40 Beta & t-stat & $\mathbf{R}^{2}$ \\
\hline ASA & 0,1078 & 0,169 & 0,7036 & 2,414 & 0,203 & $-0,3943$ & $-2,11$ & 0,7759 & 5,861 & 0,348 \\
\hline FSR & $-0,1757$ & $-0,472$ & 0,6786 & 4,1 & 0,347 & $-0,552$ & $-3,221$ & 0,723 & 4,396 & 0,455 \\
\hline IPL & $-0,7726$ & $-2,781$ & 0,7688 & 4,321 & 0,392 & $-0,5796$ & $-4,839$ & 1,0104 & 7,311 & 0,351 \\
\hline LGL & $-0,3156$ & $-0,358$ & 0,3904 & 1,531 & 0,174 & $-0,3792$ & $-3,069$ & 0,5666 & 7,106 & 0,225 \\
\hline MTN & $-0,8996$ & $-1,539$ & 0,8054 & 2,087 & 0,172 & $-0,7407$ & $-3,391$ & 1,0051 & 6,389 & 0,285 \\
\hline NED & $-0,2691$ & $-0,637$ & 0,7464 & 3,807 & 0,265 & $-0,6614$ & $-2,297$ & 0,4919 & 1,562 & 0,209 \\
\hline NPK & $-0,8735$ & $-1,244$ & 0,7009 & 2,109 & 0,156 & $-0,1672$ & $-1,55$ & 0,3933 & 2,695 & 0,219 \\
\hline NPN & $-0,8853$ & $-1,005$ & 1,4516 & 2,571 & 0,28 & $-0,2762$ & $-1,652$ & 0,8488 & 3,725 & 0,177 \\
\hline NTC & 0,4466 & 1,028 & 0,8231 & 5,667 & 0,124 & 0,0085 & 0,046 & 0,3076 & 1,834 & 0,062 \\
\hline PIK & $-0,5966$ & $-1,465$ & 0,3912 & 2,245 & 0,119 & $-0,255$ & $-2,188$ & 0,4646 & 3,634 & 0,125 \\
\hline RMH & $-0,0196$ & $-0,039$ & 0,73 & 3,403 & 0,342 & $-0,536$ & $-4,462$ & 0,8575 & 7,485 & 0,492 \\
\hline SBK & $-0,0814$ & $-0,25$ & 0,7055 & 4,635 & 0,402 & $-0,3882$ & $-4,295$ & 0,8285 & 7,354 & 0,439 \\
\hline SLM & $-0,4889$ & $-1,593$ & 0,3549 & 1,401 & 0,262 & $-0,5581$ & $-4,854$ & 1,067 & 8,071 & 0,409 \\
\hline TBS & $-0,3297$ & $-0,724$ & 0,0807 & 0,415 & 0,058 & $-0,101$ & $-1,08$ & 0,6349 & 6,286 & 0,344 \\
\hline TKG & & & & & & $-0,5975$ & $-1,936$ & 0,3391 & 0,83 & 0,108 \\
\hline VNF & 0,0718 & 0,223 & 1,0413 & 3,492 & 0,468 & $-0,0131$ & $-0,088$ & 0,6205 & 4,031 & 0,391 \\
\hline WHL & $-0,2585$ & $-0,55$ & 0,3717 & 1,14 & 0,073 & $-0,4204$ & $-2,58$ & 0,612 & 2,573 & 0,235 \\
\hline BAW & $-0,5184$ & $-1,093$ & 1,0247 & 5,594 & 0,47 & $-0,3458$ & $-3,128$ & 0,8512 & 5,331 & 0,44 \\
\hline BVT & $-0,535$ & $-1,757$ & 0,5691 & 3,245 & 0,368 & $-0,3203$ & $-1,604$ & 0,6335 & 3,236 & 0,274 \\
\hline INL & $-1,0236$ & $-2,823$ & 0,9009 & 4,937 & 0,464 & $-0,6022$ & $-2,084$ & 0,8257 & 2,282 & 0,178 \\
\hline OML & $-0,6092$ & $-3,518$ & 0,6695 & 6,305 & 0,624 & $-0,0637$ & $-0,47$ & 0,782 & 4,884 & 0,352 \\
\hline REM & $-0,4152$ & $-0,915$ & 0,5211 & 4,134 & 0,214 & 0,1491 & 0,883 & 0,6445 & 4,774 & 0,369 \\
\hline SAB & 0,2041 & 0,52 & 0,8805 & 4,461 & 0,355 & 0,0657 & 0,467 & 0,6716 & 5,207 & 0,486 \\
\hline SHF & $-0,0556$ & $-0,134$ & 0,5543 & 2,023 & 0,192 & 0,2682 & 1,456 & 0,6748 & 13,54 & 0,405 \\
\hline LBT & 0,6702 & 1,79 & 0,4058 & 3,169 & 0,318 & 0,5279 & 5,686 & 0,5627 & 6,518 & 0,594 \\
\hline RCH & 0,0598 & 0,208 & 0,5896 & 4,759 & 0,436 & 0,0673 & 0,336 & 1,1873 & 5,305 & 0,566 \\
\hline AGL & 0,4763 & 2,234 & 1,334 & 8,595 & 0,704 & 0,1557 & 1,153 & 1,4527 & 12,21 & 0,756 \\
\hline AMS & 0,1381 & 0,133 & 1,2924 & 4,444 & 0,452 & 0,6496 & 3,43 & 1,465 & 7,768 & 0,632 \\
\hline ANG & $-0,4087$ & $-1,152$ & 0,4989 & 2,131 & 0,202 & $-0,1956$ & $-0,686$ & 0,9279 & 2,913 & 0,3 \\
\hline BIL & 0,4009 & 0,452 & 1,3685 & 4,8 & 0,631 & 0,1552 & 1,136 & 1,0878 & 8,232 & 0,632 \\
\hline GFI & $-0,4326$ & $-0,765$ & 0,5329 & 1,452 & 0,073 & 0,3288 & 1,303 & 1,1299 & 4,568 & 0,312 \\
\hline HAR & 0,1875 & 0,361 & 0,4847 & 1,445 & 0,06 & 0,6168 & 1,592 & 1,521 & 2,949 & 0,382 \\
\hline KMB & & & & & & 0,335 & 1,058 & 1,2173 & 3,132 & 0,45 \\
\hline MLA & & & & & & $-0,1689$ & $-0,418$ & 0,5029 & 1,47 & 0,118 \\
\hline IMP & 0,6523 & 0,519 & 1,4653 & 5,266 & 0,482 & 0,3007 & 1,062 & 1,0812 & 4,697 & 0,513 \\
\hline SAP & $-0,2928$ & $-0,34$ & 1,5977 & 5,732 & 0,457 & 0,2693 & 1,121 & 0,6463 & 3,947 & 0,318 \\
\hline SOL & 0,4367 & 1,035 & 1,3671 & 12,18 & 0,469 & 0,7455 & 3,482 & 0,7012 & 3,275 & 0,591 \\
\hline ECO & $-0,835$ & $-0,599$ & 0,7629 & 1,365 & 0,021 & $-0,4603$ & $-2,119$ & 0,546 & 2,711 & 0,215 \\
\hline INP & $-1,0236$ & $-2,823$ & 0,9009 & 4,937 & 0,464 & $-0,1947$ & $-0,697$ & 0,8289 & 3,061 & 0,207 \\
\hline PPC & $-0,1173$ & $-0,513$ & 0,5674 & 2,924 & 0,151 & $-0,677$ & $-3,599$ & 0,5649 & 2,663 & 0,232 \\
\hline
\end{tabular}




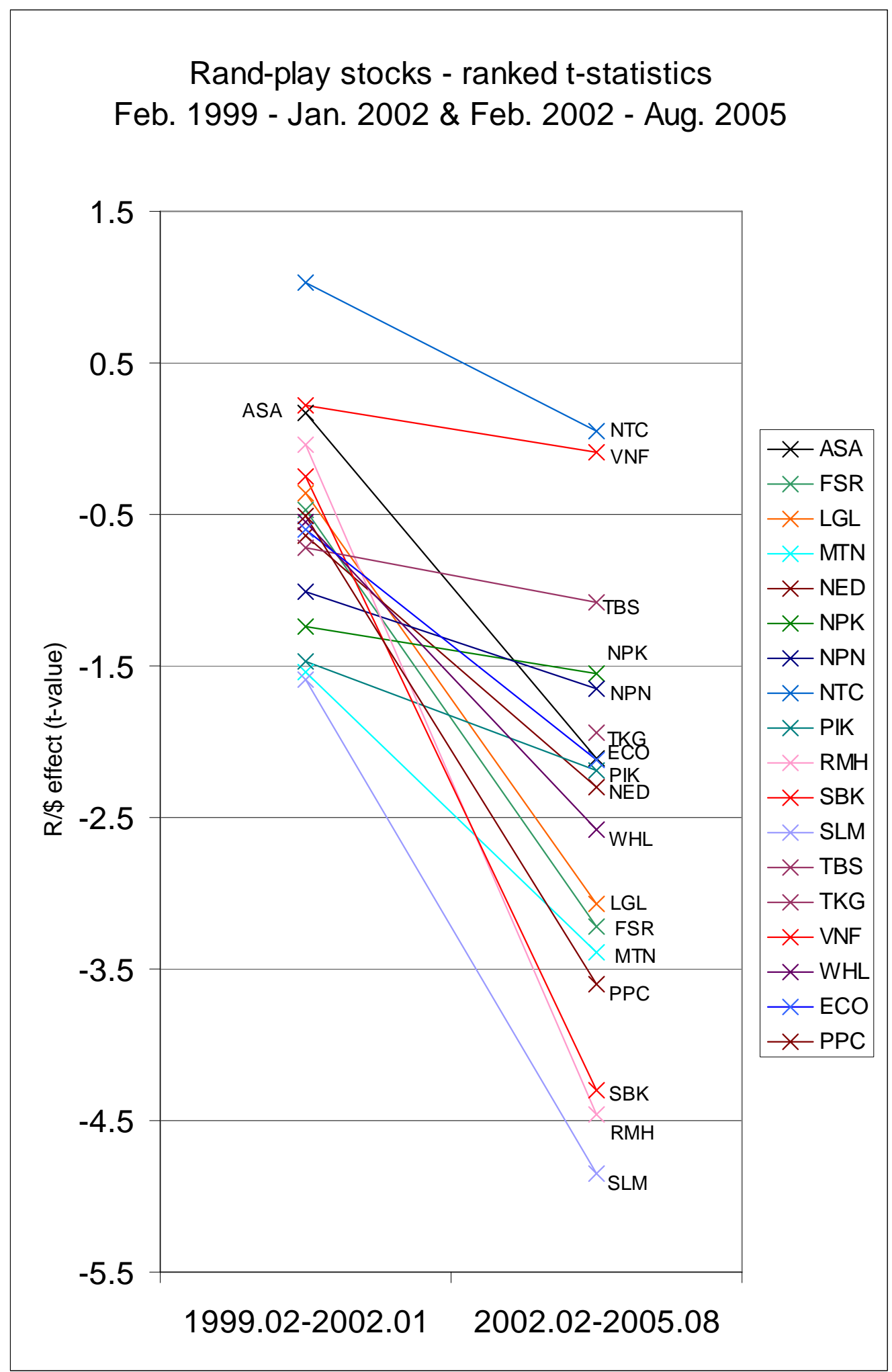

Figure 1: Rand-play stocks: Comparing the ranking of the Rand Exchange rate effect (t-statistic) over the periods February 1999 to January 2002 with February 2002 to August 2005 


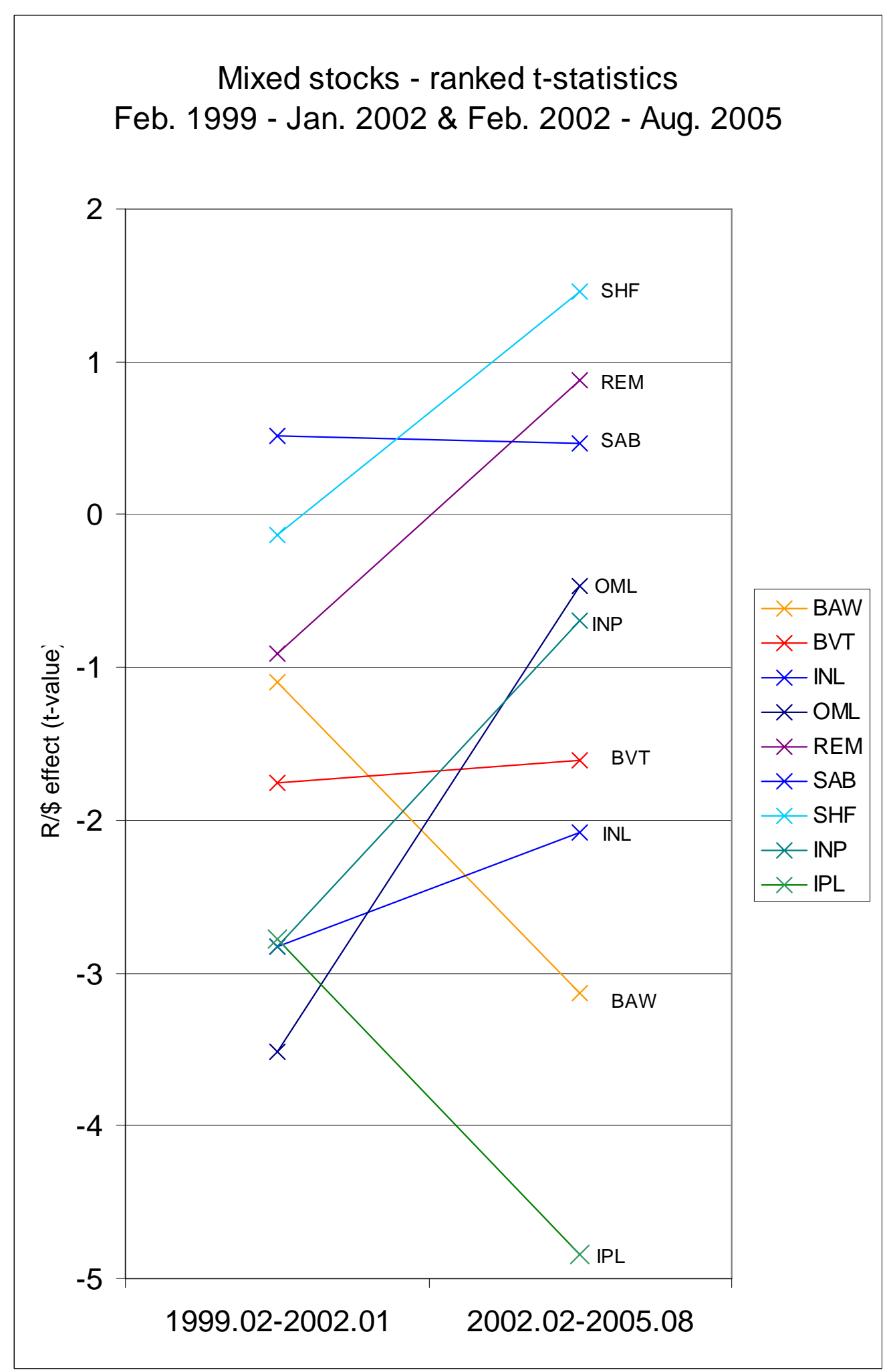

Figure 2: Mixed stocks: Comparing the ranking of the Rand Exchange rate effect (t-statistic) over the periods February 1999 to January 2002 with February 2002 to August 2005 


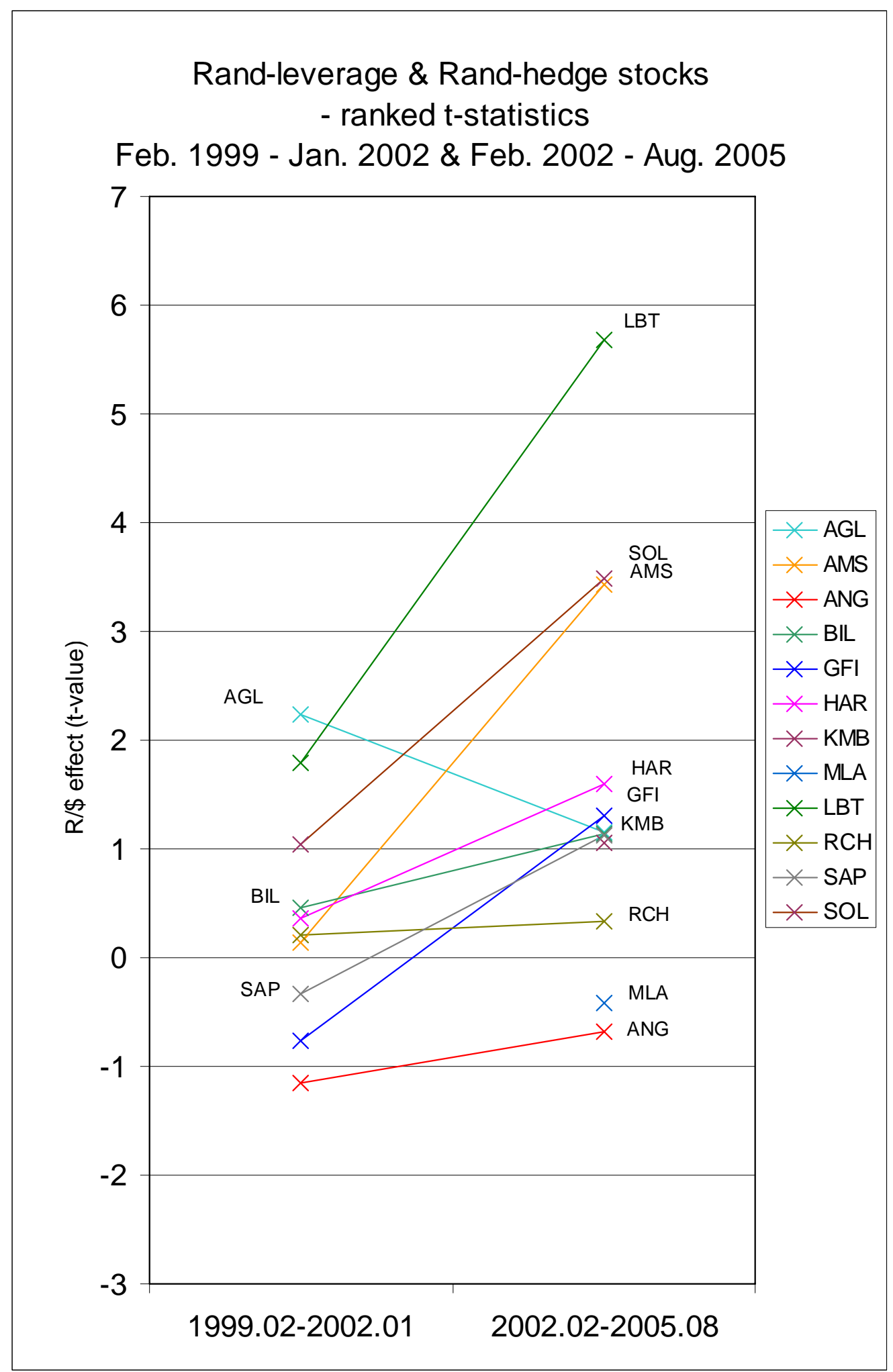

Figure 3: Rand-leverage \& Rand-hedge stocks: Comparing the ranking of the Rand Exchange rate effect (t-statistic) over the periods February 1999 to January 2002 with February 2002 to August 2005 


\section{Rand-hedge and rand-leverage}

Liberty International has behaved in a stable and strong way on the London market and this has given it a very strong Rand effect, whereas Richemont has followed a more unstable path in Zurich which has caused the estimated Rand effect to be much less significant. Liberty International along with Sasol, appear to represent the best protection against Rand weakness. It should be noted how much more protection they offer than the traditional 'hedge' shares, that is, resources. Apart from the notable exceptions of AngloGold and Mittal, all the Rand-Leverage shares exhibited positive Rand sensitivity in the latter period, which again points to the robustness of the analysis. Viewed in terms of the t-statistics, Sasol and Angloplat represent the best Randleveraged protection against Rand weakness. The gold counters clearly suffer from the underlying weakness in the gold-mining industry that has seen the gold index fall away sharply in the past two years.

\section{Conclusion}

The large market capitalisation stocks on the JSE comprise a mixture of Rand-leverage stocks, Rand-hedge stocks and Rand-plays as well as companies which are not readily categorised into a particular category. For example, the large South African industrial conglomerates have a mix of local and foreign assets, and the large South African banks have significant proportions of their assets invested offshore. Nonetheless, the classification is strongly supported by the empirical evidence and is, furthermore, useful as a framework for analysing companies' exchange rate sensitivities. The recent period of exchange rate volatility has pulled the JSE All share Index and Top40 Index in various directions - most recently (April 2006) these indices have been hitting record highs. Over this turbulent period, the lagged impact of exchange rate changes on Randleverage stocks, and the more immediate impact on Randhedges and Rand-plays, have tended to offset one another in the market and the aggregate effect on the JSE has been moderated. Short-term movements in the JSE will, however, continue to be dominated by the direction taken by the Rand, on account of the preponderance of Rand-leverage stocks on the JSE.

\section{References}

Adler, M. \& Dumas, B. 1984. 'Exposure to currency risk: Definition and measurement', Financial Management, 13: 41-50.

Barr, G.D.I. \& Bradfield, D.J. 1989. 'Risk estimation in the thinly-traded JSE environment', South African Journal of Business Management, 20:169 - 173.

Barr, G.D.I. \& Kantor, B.S. 2005. 'The impact of the rand on the value of the Johannesburg Stock Exchange', Journal for Studies in Economics and Econometrics, 29(2): 77-95.

Bodnar, G. M. \& Gentry, W.M. 1993. 'Exchange rate exposure and industry characteristics: Evidence from Canada, Japan, and the USA', Journal of International Money and Finance, 12:29-45.
Benson, K.L. \& Faff, R.W. 2003. 'Exchange rate sensitivity of Australian international equity funds', Global Finance Journal, 14: 95-120.

Bollerslev, T. 1986. 'Generalized autoregressive conditional heteroskedasticity’, Journal of Econometrics, 31: 307-327.

Bollerslev, T., Chou, R.Y. \& Kroner, K. F. 1992. 'ARCH modelling in finance', Journal of Econometrics, 52:5-59.

Bowie D.C. \& Bradfield, D.J. 1993. 'A review of systematic risk estimation on the JSE', De Ratione, 7(1):6-22.

Brooks, R. D., Davidson, S. \& Faff, R.W. 1997. 'An examination of the effects of major political change on stock market volatility: The South African experience', Journal of International Financial Markets, Institutions and Money, 7(3):255-275.

Choi, J.J. \& Prasad, A.M. 1995. 'Exchange risk sensitivity and its determinants: A firm and industry analysis of U.S. multinationals', Financial Management, 24(3):77-88.

Di Iorio, A. \& Faff, R. 2001. 'A test of the stability of exchange rate risk. Evidence from the Australian equities market', Global Finance Journal, 12:179-203.

Dominguez, K. M. E. \& Tesar, L. L. 2001. 'A reexamination of exchange-rate exposure', American Economic Review, 91(2):396-399.

Engle, R.F. 1982. 'Autoregressive conditional heteroscedasticity with estimates of the variance of United Kingdom inflation', Econometrica, 50:987-1007.

Fama, E.F. 1965. 'The behavior of sock market prices', Journal of Business, 38(1): 34-105.

Giliberto, M. 1985. 'Interest rate sensitivity in the common stocks of financial intermediaries: A methodological note', Journal of Financial and Quantitative Analysis, 20(1):123126.

Green, W.H. 1987. Econometric analysis. New York: Prentice-Hall.

Johnson, Jr. A.C., Johnson, M.B. \& Buse, R.C. 1987. Econometrics: Basic and applied. New York: Macmillan.

Jorion, P. 1990. 'The exchange rate exposure of U.S. multinationals’, Journal of Business, 63(3):331-345.

Jorion, P. 1991. 'The pricing of exchange risk in the stock market', Journal of Financial and Quantitative Analysis, 26(3):363-376.

Khoo, A. 1994. 'Estimation of foreign exchange exposure: An application to mining companies in Australia', Journal of International Money and Finance, 13(3):342-363.

Loudon, G. 1993. 'The foreign exchange operating exposure of Australian stocks', Accounting and Finance, 33:19-32. 
Mandelbrot, B. 1963. 'The variation of certain speculative prices’, Journal of Business, 36(3): 394-419.

Sharpe, W.F. 1994. 'The Sharpe Ratio', Journal of Portfolio Management, Fall: 49-58.

Youguo, L. \& Mbodja, M. 1996. 'The pricing of foreign risk: Evidence from ADRs', International Review of Economics \& Financ, 5(4):377-385.

Ziliak, S. T. \& McCloskey, D.N. 2004. 'Size matters: The standard error of regressions in the American Economic Review', The Journal of Socio-Economics, 33(5):527-546. 


\section{APPENDIX}

\section{Share Prices And Leverage On The JSE: A Formal Treatment}

Share prices on the JSE clearly reflect the market's best attempt to find the present value of the expected benefits from owning a share of the company. These benefits will be derived from expected future earnings and dividends or from the sale or liquidation of the company.

These earnings and dividend flows from JSE listed companies may be generated from:

a) company operations that are almost completely SAbased. We define these companies listed on the JSE as Rand-plays, e.g. retailers (such as Pick 'n Pay) or banks (such as Absa) with almost all their revenues generated and costs incurred in South Africa in Rands;

b) companies listed on the JSE that are almost completely foreign based, generating only foreign 'hard' currency income and incurring only foreign costs and known as Rand-hedge stocks, e.g. Liberty International, a UK property owner and developer, or Richemont;

c) companies that are SA-based and incur costs in SA but sell their products in hard currency, e.g. resource stocks such as Harmony, which we describe as Rand-leverage stocks.

We consider the dividend at time $t$ (expressed in Rands) and denoted Div ${ }_{t}$ for each of the cases above:

a) Rand-play: $\operatorname{Div}_{\mathrm{t}}$ is proportional to profit at time t,

(R) $\operatorname{Rev}_{\mathrm{t}}-(\mathrm{R}) \operatorname{Cost}_{\mathrm{t}}$

b) Rand-hedge: $\operatorname{Div}_{\mathrm{t}}$ is proportional to profit at time $\mathrm{t}$ denominated in, say, US dollars and then converted into Rand to give,

$\mathrm{R} / \$ \mathrm{t} *\left(\$ \operatorname{Rev}_{\mathrm{t}}-\$ \operatorname{Cost}_{\mathrm{t}}\right)$

hence the profits of a Rand-hedge company in dollars will be directly impacted upon by the Rand/US\$ exchange rate; a weaker exchange rate will increase the dividend flow in Rands for any given profit in dollars.

c) Rand-leverage: in the third group (typically resource companies), the Rand price of their shares reacts to the dollar prices of their traded resources as well as to the Rand/US\$ exchange rate. A weaker Rand increases the Rand price of commodities and lowers the dollar-denominated costs of inputs, mainly labour. This effect would, primarily, be a short-term effect. Prices and particularly labour costs would be expected to rise as a PPP equilibrium was re-established and the real Rand depreciation eliminated. Thus, a weaker Rand would result in an increase in dollar earnings for as long as dollar costs were below their PPP value; as PPP is re-established, dollar prices of labour would rise.

In this case, as in (b) above, $\operatorname{Div}_{t}$ is proportional to dollar profit at time $\mathrm{t}$ denominated in dollars and then converted into Rands. Although revenues are earned in dollars, costs are denominated in Rands to give dollar profit at time t:

$$
\mathrm{R} / \$_{\mathrm{t}} *\left(\$ \operatorname{Rev}_{\mathrm{t}}-(\mathrm{R}) \operatorname{Cost}_{\mathrm{t}} *(1 / \mathrm{R} / \$ \mathrm{t})\right)
$$

However, Rand costs rise in line with the consumer price index. Thus, dollar costs will be linked to the relative movement of the CPI and the exchange rate. At time $t+n$, dollar profit will be:

$$
\mathrm{R} / \$_{\mathrm{t}+\mathrm{n}} *\left(\$ \operatorname{Rev}_{\mathrm{t}+\mathrm{n}}-(\mathrm{R}) \operatorname{Cost}_{\mathrm{t}} *\left(\mathrm{CPI}_{\mathrm{t}+\mathrm{n}} / \mathrm{CPI}_{\mathrm{t}}\right) *\left(1 / \mathrm{R} / \$_{\mathrm{t}+\mathrm{n}}\right)\right)
$$

Thus, assuming dollar revenues are fairly stable, dollar profits $n$ periods in the future are determined by the relative movement of the CPI to the Rand/US\$ exchange rate over the $\mathrm{n}$ periods. For example, Rand depreciation will lower dollar costs and create a leveraged effect on dollar profits. But, as CPI catches up over time with any depreciation in the Rand (or vice versa) and PPP is re-established, the leverage effect dissipates and the short-term improvement in dollar profits due to the real Rand depreciation disappears. In other words, leverage effects measured in dollars which stem from an exchange rate depreciation are merely shortterm effects and do not fundamentally affect long term value.

In Rand terms, prices should reflect these leveraged dollar effects values but, assuming PPP will hold, the long term value should primarily be determined by expectations of dollar-denominated resource prices and expectations of Rand/US\$ exchange rates. 
